\title{
Effectors from Wheat Rust Fungi Suppress Multiple Plant Defense Responses
}

\author{
Sowmya R. Ramachandran, Chuntao Yin, Joanna Kud, Kiwamu Tanaka, Aaron K. Mahoney, \\ Fangming Xiao, and Scot H. Hulbert
}

First, second, fourth, fifth, and seventh authors: Department of Plant Pathology, Washington State University, Pullman, WA 99164-6430; and third and sixth authors: Plant, Soil and Entomological Sciences, University of Idaho, Moscow, ID 83844-2339. Accepted for publication 30 July 2016.

\begin{abstract}
Fungi that cause cereal rust diseases (genus Puccinia) are important pathogens of wheat globally. Upon infection, the fungus secretes a number of effector proteins. Although a large repository of putative effectors has been predicted using bioinformatic pipelines, the lack of available highthroughput effector screening systems has limited functional studies on these proteins. In this study, we mined the available transcriptomes of Puccinia graminis and P. striiformis to look for potential effectors that suppress host hypersensitive response (HR). Twenty small $(<300$ amino acids), secreted proteins, with no predicted functions were selected for the HR suppression assay using Nicotiana benthamiana, in which each of the proteins were transiently expressed and evaluated for their ability to

R gene-Pto(Y207D). Nine out of twenty proteins, designated Shrl to $S h r 9$ (suppressors of hypersensitive response), were found to suppress HR in $\bar{N}$. benthamiana. These effectors varied in the effector-R gene defenses they suppressed, indicating these pathogens can interfere with a variety of host defense pathways. In addition to HR suppression, effector $\operatorname{Shr} 7$ also suppressed PAMP-triggered immune response triggered by flg22. Finally, delivery of $\operatorname{Shr} 7$ through Pseudomonas fluorescens EtHAn suppressed nonspecific HR induced by Pseudomonas syringae DC3000 in wheat, confirming its activity in a homologous system. Overall, this study provides the first evidence for the presence of effectors in Puccinia species suppressing multiple plant defense responses.
\end{abstract} suppress HR caused by four cytotoxic effector-R gene combinations $(C p / R x, A T R 13 / R P P 13, R p t 2 / R P S-2$, and GPA/RBP-1) and one mutated
Additional keywords: reactive oxygen species.
The rust diseases, caused by basidiomycetous fungi of the genus Puccinia, are serious production constraints in all wheat production regions, leading to epidemic outbreaks on susceptible varieties under favorable climatic conditions. Three species of the fungus, Puccinia graminis f. sp. tritici, P. triticina, and P. striiformis f. sp. tritici, cause stem, leaf, and stripe rust, respectively. Despite best efforts to control the disease by fungicide application, use of resistant varieties and cultural practices like host free periods, the disease continues to affect production across the globe (Han et al. 2015; Hovmøller et al. 2008). Efficient management of rust becomes a challenge due to the ability of rust fungus populations to produce vast number of asexual spores throughout the cropping season that spread over long distances and to alter their repertoire of effectors that are detected by the resistance genes deployed in commercial cultivars (Hovmøller et al. 2008; Kolmer 2005).

Plant proteins that detect pathogens and trigger defense responses are typically grouped into two types (Jones and Dangl 2006; Thomma et al. 2011). Pattern recognition receptors (PRRs) detect conserved pathogen-associated molecular patterns (PAMPs) or microbial-associated molecular patterns (MAMPs) and trigger responses conferring PAMP-triggered immunity (PTI). Common components of PTI include callose deposition, production of antimicrobial compounds such as reactive oxygen species (ROS), and accumulation of defense proteins. Effector-triggered immunity (ETI) constitutes the second, more robust line of defense of the host.

Corresponding author: S. H. Hulbert; E-mail address: scot_hulbert@wsu.edu

*The $e$-Xtra logo stands for "electronic extra" and indicates that three supplementary tables are published online.

(C) 2017 The American Phytopathological Society
This is triggered in response to certain pathogen effector molecules secreted by pathogens during the infection process. Recognition of the effector molecules or their effects in the cell, by resistance proteins, leads to programmed cell death (PCD) along with other responses, some of which are more systemic. ETI-triggered PCD, known as the hypersensitive response (HR), can be particularly effective against biotrophic pathogens but can, in some cases, promote colonization by necrotrophic pathogens (Faris et al. 2010; Lorang et al. 2007).

Many plant pathogens secrete effectors that function to subvert host defense responses or enhance their success in pathogenicity in other ways. The best-characterized effectors are those from bacterial pathogens which deliver effectors to plant cells via their type III secretion system to suppress both PTI and ETI (Block and Alfano 2011; Lindeberg et al. 2012). Many have specific targets in host cells whose identification has revealed novel components of plant immune systems (Feng and Zhou 2012). Numerous effectors from oomycete pathogens have also been identified, which has been facilitated by their conserved protein motifs (Fabro et al. 2011; Whisson et al. 2007). A role in suppression of cell death has been demonstrated for many of these effectors by co-expression in Nicotiana benthamiana with proteins that trigger cell death (Bos et al. 2006; Dou et al. 2008; Kelley et al. 2010; Oh et al. 2009; Wang et al. 2011). A large-scale analysis of oomycete and bacterial effectors found they interacted with some of the same host proteins indicating they share targets for modulating defense (Mukhtar et al. 2011). Unlike bacterial and oomycete pathogens, large-scale functional analyses of fungal effectors have been hindered in part by a lack of conserved sequences to aid their identification although computational approaches coupled with expression analysis are addressing this challenge (Godfrey et al. 2010; Pedersen et al. 2012; Saunders et al. 2012; Sperschneider et al. 2015). A growing number of fungal effectors known to interact with plant $\mathrm{R}$ genes have been 
identified and found to be very diverse in their structures, evolutionary origins, proposed functions, and locations in plant cells (Giraldo and Valent 2013).

Like many other biotrophic fungi, rust fungi produce specialized feeding structures called haustoria, which penetrate plant cell walls and are separated from the cytoplasm by an extrahaustorial membrane. The haustorium forms an intimate association with the host plant, facilitating the uptake of nutrients and delivery of effector proteins (Garnica et al. 2014). Relatively small proteins expressed in haustorial cells with sequence motifs indicating secretion are considered to be good candidates for effector proteins (Ahmed et al. 2015; Liu et al. 2016; Petre et al. 2015; Whigham et al. 2015; Yin et al. 2015). Most, but not all (Nirmala et al. 2011), of the rust effectors identified, that function as avirulence proteins and interact with resistance proteins, fit the description of small, secreted proteins (Catanzariti et al. 2006, 2007; Dodds et al. 2004; Jia et al. 2000). Recent efforts have provided genome and transcriptome sequences along with gene expression and polymorphism analyses for the three Puccinia species that infect wheat (Bruce et al. 2014; Cantu et al. 2011, 2013; Garnica et al. 2013; Hubbard et al. 2015; Xu et al. 2011; Yin et al. 2015; Zheng et al. 2013). Candidate effector proteins are therefore very abundant, but few have been analyzed for function. In this study, we mined putative effector candidates from the available transcriptome of Puccinia graminis and P. striiformis. Twenty putative effector proteins were selected and expressed in $N$. benthamiana to test for their ability to suppress HR. Nine (Shrl to Shr 9 ) out of the 20 proteins screened were found to suppress cell death caused by different elicitors indicating their possible role in suppressing ETI.

\section{MATERIALS AND METHODS}

Plant material, fungal strains, and growth conditions. Plants used in this study included Nicotiana benthamiana and the wheat cultivars McNair701, Avocet, and Nugaines. N. benthamiana plants were grown from seed in the greenhouse at $24^{\circ} \mathrm{C}$ day and $20^{\circ} \mathrm{C}$ night. Four- to six-week-old $N$. benthamiana plants were used for cell death suppression assays. Wheat cultivar Avocet was infected with $P$. striiformis race PSTv37 (PST-100) for urediniospore increase and RT-qPCR analysis. Wheat leaves were infected by spreading a 10:1 mixture of talc/urediniospores on the leaves and incubating in a dew chamber for $24 \mathrm{~h}$ at $10^{\circ} \mathrm{C}$ with $100 \%$ relative humidity. The next day, plants were moved to a growth chamber with $16 \mathrm{~h}$ light at $16^{\circ} \mathrm{C}$ and $8 \mathrm{~h}$ dark at $8^{\circ} \mathrm{C}$ until the infected leaves began to sporulate. McNair 701 plants were infected with urediniospores of $P$. graminis CRL 75-36-700-3 race SCCL (Pgt7A) as previously described (Yin et al. 2011). Wheat leaves infected with fungal spores were harvested at different stages of infection (6 and 10 days postinoculation [dpi]) for RT-qPCR analysis. Fresh fungal spores were collected and stored at $-80^{\circ} \mathrm{C}$ for RNA extraction or until further use. Germinated spores were obtained by floating fungal spores on sterile distilled water on a glass petri dish overnight in dark. Germinated spores were collected from the surface of the water and used for RNA extraction.

Effector selection and plasmid construction. Candidate effector genes were selected based on the following criteria for their predicted proteins: (i) size less than 300 amino acids; (ii) presence of a signal peptide (predicted using SignaIP 4.0); and (iii) no significant homology to proteins with predicted functions. In addition, candidate $P$. graminis effectors were selected from transcripts that appeared to be enriched in haustoria cells from transcriptome data as described by Yin et al. (2015). P. striiformis were selected from PSTv37 (PST-100) based on their protein sequence homology ( $>80 \%)$ to effectors predicted by Cantu et al. (2011). Homology searches were conducted on the Broad Institute Puccinia Database using BLASTP $(P<1.0 \mathrm{E}-10)$. Genes were amplified from rust-infected wheat tissue cDNA using primers designed to amplify only the coding sequence of the mature protein without the signal peptide (Supplementary Table S1). Effector genes were cloned into an Agrobacterium binary vector pBTEX between restriction sites $K p n \mathrm{I}$ and $X b a \mathrm{I}$ and expressed transiently in $N$. benthamiana. Effectors were cloned into pBTEX without a stop codon in fusion with a 6X FLAG tag at the $3^{\prime}$ end. Primers were designed to generate truncations of gene $\operatorname{Shr} 7$ which were also cloned into pBTEX (Supplementary Table S2). P. graminis f. sp. tritici IaaM was cloned into Agrobacterium binary vector pCHF3 (Yin et al. 2014). All constructs were verified by sequencing at Elim Biopharm, Hayward, CA.

Agrobacterium-mediated transient assay. For transient expression of proteins, all constructs were electroporated into Agrobacterium GV2260. Six- to eight-week-old N. benthamiana plant leaves were infiltrated with the bacterial suspensions as described previously by Sessa et al. (2000). Only the second to fourth leaves of the plants were chosen for inoculations. All gene constructs and cell death elicitors were diluted to an optical density $\left(\mathrm{OD}_{600}\right)$ of 0.4 to 0.6 and infiltrated into leaves using a needle-less syringe. For zero hour infiltrations, effector gene constructs and HR constructs were mixed in a 1:1 ratio before infiltration. For $24 \mathrm{~h}$ staggered inoculations, the Agrobacterium strain containing the putative effector genes were infiltrated $24 \mathrm{~h}$ prior to the cell death causing constructs. Effector constructs ATR13, Cp, AvrRpt2, and $R B P-1$ were mixed with their corresponding R genes; $R P P 13, R x$, $R P S-2$, and $G P A$, respectively, in a 1:1 ratio before infiltration. Each putative effector gene was tested on four leaves and the experiment was repeated three separate times. Development of cell death was monitored over a period of 5 to 7 days and leaves were photographed at 5 dpi.

Quantification of HR. HR was quantified using LeafQuant, a matlab-based image processing package. Briefly, images were loaded onto LeafQuant-T3S and the inoculated area was selected using the elliptical selection tool. ExposureVal was set at 1.2 for all images. Twelve inoculated spots were analyzed for each gene. Average percent reduction in HR was calculated by the formula (percent nongreen area for green fluorescent protein (GFP) percent nongreen area for effector) $\times 100$ /percent nongreen area for GFP. Analysis of variance was performed to test for statistical significance using JMP software (SAS Institute, Inc., Cary, NC) and Microsoft Excel.

Quantitative PCR analysis. The expression of the nine identified effector proteins was determined using quantitative PCR. Total RNA was isolated from infected wheat leaves, urediniospores, and germinated urediniospores using TRIzol reagent (Thermo Fischer Scientific, Waltham, MA) according to manufacturer's protocol. cDNA was synthesized using iScript reverse transcription Supermix for RT-qPCR (Bio-Rad, Hercules, CA). Real-time quantitative PCR was performed using iTaq Universal SYBR Green Supermix (Bio-Rad). PCR was performed on the My iQ Single Color Real-Time PCR detection system (Bio-Rad) under the following conditions: $95^{\circ} \mathrm{C}$ for $3 \mathrm{~min}, 95^{\circ} \mathrm{C}$ for $15 \mathrm{~s}, 60^{\circ} \mathrm{C}$ for $45 \mathrm{~s}$; followed by a dissociation program to obtain the melting curves. Actin genes specific for $P$. striiformis and $P$. graminis were used as internal reference controls to calculate relative gene expression for $P$. striiformis and $P$. graminis effectors, respectively. Relative gene expression was calculated using the $2^{-\Delta \Delta C T}$ approach (Schmittgen and Livak 2008) with three biological replicates for each effector gene.

ROS measurement. Measurement of ROS was performed using a luminol-based chemiluminescence assay as described previously (Gimenez-Ibanez et al. 2009). Briefly, leaf discs $(0.5 \mathrm{~cm}$ in diameter) from pre-infiltrated $N$. benthamiana leaves were floated overnight on $500 \mu \mathrm{l}$ of water in a 24 -well plate. The following day, water was carefully aspirated out of the wells and replaced with $300 \mu \mathrm{l}$ of oxidative burst solution containing horseradish peroxidase at $20 \mu \mathrm{l} / \mathrm{ml}$ (Sigma, St. Louis, MO), luminol at $34 \mu \mathrm{g} / \mathrm{ml}$ (Sigma), and $100 \mathrm{nM}$ flg22. Luminescence was measured every $2 \mathrm{~min}$ for a period of $30 \mathrm{~min}$ total using a multimode 
plate reader (Enspire 2300; Perkin Elmer, Turku, Finland), and results were analyzed using JMP software (SAS Institute, Inc.) and Microsoft Excel.

Plasmid construction for expression via type III secretion system. PCR products for GFP, and PSTG_14695 were cloned into Gateway entry vector pCR8 using TA cloning. Plasmids containing the genes were then transferred to destination vector pEDV6 using LR reaction and transformed into electrocompetent Pseudomonas fluorescens strain EtHAn (effector to host analyzer) provided by Jeff Chang (Oregon State University). pEDV6 contains the AvrRps4 promoter along with the first 137 amino acids of AvrRps4 at its $\mathrm{N}$ terminal. The $\mathrm{N}$ terminal region of AvrRps4 provides the necessary signal for secretion of the cloned protein through the type III secretion system of Pseudomonas.

Wheat assay. Pseudomonas cells were grown in King's B media for $48 \mathrm{~h}$ at $28^{\circ} \mathrm{C}$ using appropriate antibiotics, washed once, and resuspended in sterile double-distilled water. Pseudomonas fluorescens and Pseudomonas syringae DC3000 suspensions were diluted to an $\mathrm{OD}_{600}$ of 1.0 and Pseudomonas fluorescens strain containing GFP and the candidate suppressors was grown for $48 \mathrm{~h}$ at $28^{\circ} \mathrm{C}$ in $\mathrm{KB}$ media supplemented with chloramphenicol, tetracycline, and gentamycin at $25 \mu \mathrm{g} / \mathrm{ml}$. Pseudomonas syringae DC3000 was grown in $\mathrm{KB}$ media containing rifampicin at $25 \mu \mathrm{g} / \mathrm{ml}$ and ampicillin at $100 \mu \mathrm{g} / \mathrm{ml}$. Bacterial cells were washed once and resuspended in sterile double-distilled water. Pseudomonas fluorescens cells were diluted to an $\mathrm{OD}_{600}$ of 0.6 and Pseudomonas syringae was diluted to an $\mathrm{OD}_{600}$ of 0.3 . The two bacterial solutions were mixed in a 1:1 ratio and infiltrated into 10- to 14-day-old wheat leaves (cultivar Nugaines). Results were repeated at least three times. Photographs of treated leaves were taken $3 \mathrm{dpi}$ and used for quantification. A total of 11 leaves were selected for statistical analysis.

\section{RESULTS}

Selection of candidate effectors. A diverse collection of 20 candidate effector proteins were selected based on their small size (105 to 270 amino acids), predicted signal peptide, and lack of homology to proteins with known functions. Nine were selected from $P$. striiformis sequences and 11 from $P$. graminis (Table 1). In addition to small size and the presence of a signal peptide, many effectors are known to have high cysteine content (Kamoun 2007). In this study, all genes except for PGTG_07550, PGTG_08644, PGTG_10751, and PGTG_13212 contained more than 2\% cysteine residues in their predicted proteins. $P$. graminis genes were selected from the list of 1,182 haustorium-enriched genes sequences provided by Yin et al. (2015). For P. striiformis genes, a list of effectors predicted by Cantu et al. (2011) was used as a reference and transcripts coding for homologous proteins were chosen from the PST-78 sequence database (Broad Institute Puccinia Group Database). When used in homology searches (BLASTP) against the Broad Database, 15 of the 20 effectors were found to belong to gene families with 2 to 37 family members $(P<1.0 \mathrm{E}-10)$. Most of the genes, especially those belonging to gene families, had conserved homologs in two or more of the three Puccinia species with sequenced genomes; $P$. striiformis, $P$. graminis, and $P$. triticina. The largest gene families, with 15 or more members, had homologs in all three Puccinia species (Table 1).

Suppression of HR. To test whether the effector genes could suppress PCD, candidate effector genes were either co-infiltrated or infiltrated $24 \mathrm{~h}$ before the HR constructs into 4- to 6-week-old $N$. benthamiana plants. When inoculated $24 \mathrm{~h}$ prior to the HR-causing constructs, two $P$. graminis (Shr8 and Shr9) and seven P. striiformis effectors ( $S h r 1$ to $S h r 7)$ were able to suppress cell death induced by at least one of the six HR elicitors used (Table 2). However, suppression was not observed with any of the effectors when infiltrated simultaneously with the HR construct. Shr1, Shr2, Shr4, $S h r 5$, and $S h r 7$ suppressed cell death caused by Pto(Y207D) when inoculated $24 \mathrm{~h}$ prior to the Agrobacterium strain carrying Pto (Y207D) (Fig. 1A; Table 2). When compared with the GFP control, most proteins that suppressed HR inhibited cell death in more than half of the leaf area infiltrated with the cell death construct (Table 2). Shr4, Shr5, and Shr7 showed nearly complete suppression, resulting in $74.4,74.9$, and $81 \%$ reduction in HR, respectively. All other effectors showed less complete suppression of PCD (Table 2; Supplementary Table S3). The representative phenotype observed for less complete suppression by Shr8 is shown in Figure 1B. Shrl and $S h r 7$ suppressed cell death caused by $A T R 13 / R P P 13$, while

TABLE 1. Summary of candidate effector genes tested for suppression of cell death

\begin{tabular}{|c|c|c|c|c|c|c|c|}
\hline $\begin{array}{l}\text { Candidate } \\
\text { effector gene }\end{array}$ & $\begin{array}{c}\text { Copy } \\
\text { number }\end{array}$ & $\begin{array}{c}\text { Protein } \\
\text { length (aa) }\end{array}$ & $\begin{array}{l}\text { Position of } \\
\text { signal peptide }\end{array}$ & Cysteine (\%) & $\begin{array}{l}\text { Conservation in } \\
\text { Puccinia sp. }\end{array}$ & Tribe $^{c}$ & $\begin{array}{c}\text { Protein } \\
\text { expression }^{\mathrm{d}}\end{array}$ \\
\hline \multicolumn{8}{|l|}{ P. striiformis } \\
\hline PSTG_00494 & 15 & 199 & 23 & 3.09 & PSTG,PGTG,PTTG & 19 & - \\
\hline PSTG_01062 & 3 & 182 & 22 & 5.92 & PSTG,PGTG,PTTG & 148 & - \\
\hline PSTG_01724 & 4 & 114 & 24 & 5.26 & PSTG, PGTG & 149 & + \\
\hline PSTG_09266 & 8 & 191 & 19 & 4.28 & PSTG, PGTG & 31 & - \\
\hline PSTG_10812 & 2 & 105 & 20 & 4.76 & PSTG & 619 & + \\
\hline PSTG_12529 & 1 & 173 & 26 & 3.9 & PSTG & 361 & + \\
\hline PSTG_14250 & 6 & 199 & 19 & 6.09 & PSTG, PGTG & 31 & - \\
\hline PSTG_14695 & 1 & 151 & 19 & 3.52 & PSTG,PGTG,PTTG & 696 & + \\
\hline PSTG_16009 & 6 & 158 & 20 & 6.33 & PSTG,PGTG,PTTG & 11 & + \\
\hline \multicolumn{8}{|l|}{$P$. graminis } \\
\hline PGTG_00639 & 20 & 217 & 20 & 2.3 & PGTG,PSTG,PTTG & 10 & - \\
\hline PGTG_03101 & 37 & 251 & 21 & 3.9 & PGTG,PSTG,PTTG & 1 & + \\
\hline PGTG_04606 & 15 & 214 & 19 & 3.7 & PGTG,PSTG,PTTG & 5 & + \\
\hline PGTG_07550 & 1 & 128 & 19 & 0.7 & PGTG & - & - \\
\hline PGTG_08644 & 2 & 255 & 19 & 0.3 & PGTG,PSTG,PTTG & 54 & + \\
\hline PGTG_10268 & 1 & 123 & 19 & 4.8 & PGTG & - & - \\
\hline PGTG_10642 & 5 & 150 & 19 & 4.0 & PGTG,PSTG,PTTG & 125 & + \\
\hline PGTG_10751 & 1 & 235 & 18 & 1.7 & PGTG, PTTG & 1339 & - \\
\hline PGTG_13212 & 4 & 270 & 21 & 1.1 & PGTG,PSTG,PTTG & 276 & - \\
\hline PGTG_15486 & 2 & 191 & 23 & 3.1 & PGTG,PSTG,PTTG & - & + \\
\hline PGTG_17549 & 6 & 210 & 20 & 6.19 & PGTG,PSTG,PTTG & 63 & + \\
\hline P. graminis f. sp. tritici IaaM & 1 & 588 & - & 1.4 & PGTG,PSTG,PTTG & - & Not tested \\
\hline
\end{tabular}

${ }^{a}$ Number of genes encoding highly homologous proteins $(P<1.0 \mathrm{E}-10)$ predicted in the PST-78 or PGT genome (Broad Institute Database).

b Puccinia species with genes encoding highly homologous proteins $(P<1.0 \mathrm{E}-10$; Broad Institute Database).

c Tribes numbers (assigned by Cantu et al. 2013) to which the proteins belong to based on their BLASTP percentage sequence identity of $>80 \%$.

d + , protein expression detected 24 to $36 \mathrm{~h}$ postinoculation; -, protein not detected on western blot. 
Shr2, Shr3, Shr6, Shr8, and Shr9 suppressed cell death caused by GPA/RBP-1 (Table 2). Two effector genes, $S h r l$ and $S h r 7$, were able to suppress PCD caused by both Pto(Y207D) and ATR13/RPP13, while $S h r 2$ suppressed cell death induced by $P t o(Y 207 D)$ and $R B P-1 /$ $G P A$. The ability of some genes to suppress more than one PCD elicitor but not others, suggests that these effectors employ different mechanisms to interfere with host cell death. Interestingly, a majority of the effectors suppressed cell death caused by either Pto $(Y 207 D)$ or RBP-1/GPA suggesting that there might be at least two modes of actions involved in inhibition of cell death by these effectors. Taken together, these results indicate that some effectors from $P$. graminis and $P$. striiformis play a role in suppression of host HR. The similarity in suppression activities between some of the effectors suggests a functional redundancy in the effector repertoire of Puccinia. The $P$. graminis f. sp. tritici IaaM gene was used as a control in the study. While important for pathogenicity, its protein did not fit the description of a small, secreted effector protein, but rather an enzyme expressed in Puccinia haustoria (Yin et al. 2014). As expected, P. graminis f. sp. tritici IaaM did not show suppression with any of the R genes tested.

Truncations of $\boldsymbol{S h r} 7$. To validate the results obtained from suppression assays, we tested two truncations of effector protein Shr7 for their ability to suppress Pto(Y207D) and ATR13/RPP13 induced PCD. Truncations of Shr7, designated Shr7-T1 and Shr7T2 were generated where 44 and 88 amino acids, respectively, were deleted from the $\mathrm{C}$-terminal of the protein. When tested using the

TABLE 2. Suppression of programmed cell death caused by candidate effector genes from the stripe and stem rust fungi

\begin{tabular}{lcccc}
\hline & & \multicolumn{3}{c}{$\begin{array}{c}\text { Suppression of effector-triggered } \\
\text { immunity-induced HR }\end{array}$} \\
\cline { 3 - 5 } $\begin{array}{l}\text { Effector } \\
\text { designation }\end{array}$ & $\begin{array}{c}\text { Broad institute } \\
\text { designations }\end{array}$ & $\begin{array}{c}\text { Pto }(Y 207 D) \\
\text { ATR13/RPP13 }\end{array}$ & GPA/RBP-1 \\
\hline Shr1 & PSTG_00494 & 58.4 & 48.2 & - \\
Shr2 & PSTG_01062 & 63.2 & - & 42.3 \\
Shr3 & PSTG_01724 & - & - & 42.2 \\
Shr4 & PSTG_09266 & 74.4 & - & - \\
Shr5 & PSTG_10812 & 80.0 & - & - \\
Shr6 & PSTG_14250 & - & - & 59.6 \\
Shr7 & PSTG_14695 & 74.9 & 43.1 & - \\
Shr8 & PGTG_03101 & - & - & 66.6 \\
Shr9 & PGTG_10642 & - & - & 50.2 \\
\hline
\end{tabular}

a Percent reduction in hypersensitive response (HR) when Agrobacterium carrying candidate effector gene was infiltrated $24 \mathrm{~h}$ prior to Agrobacterium carrying the cell death elicitor; - indicates no noticeable suppression. suppression assay, both truncations lost their ability to suppress cell death caused by Pto(Y207D) (Fig. 2) and ATR13/RPP13 (data not shown). This confirmed the activity of the mature protein (without the signal peptide) to suppress PCD. However, further nested deletions may be required to pin-point the region responsible for suppression.

Transcription pattern of the identified effector genes. In order to assess the pattern of expression of the identified effectors, we examined the relative abundance of their corresponding transcripts during different stages of fungal development. Total RNA was extracted from urediniospores, urediniospores germinated in vitro, and infected wheat leaves 6 dpi for $P$. graminis and 10 dpi for $P$. striiformis. $P$. graminis and $P$. striiformis transcript levels for each tissue type were normalized using the $P$. graminis and $P$. striiformis actin genes, respectively. Relative gene expression for all tissue types was calculated with respect to transcript levels in urediniospores. The results from RT-qPCR results indicated that six out of nine effector genes were induced upon infection, although the level of induction varied considerably (Fig. 3). All the effectors had minimal to no expression in fungal urediniospores, indicating they are indeed effector proteins involved in pathogen colonization. Accumulation of transcripts for six genes (Shr1, Shr2, Shr4, Shr5, Shr6, and $S h r 9$ ) was highest at $10 \mathrm{dpi}$, for two genes (Shr7 and $S h r 8$ ) at 6 dpi and for one (Shr3) in the germinated urediniospores (Fig. 3). A similar 'sequential wave' in effector expression has been reported previously in P. striiformis and Phytophthora sojae (Cantu et al. 2013; Wang et al. 2011). Transcription patterns for two genes ( $\mathrm{Shr} 2$ and $S h r 4$ ), had higher expression levels in germinated urediniospores and at 10 dpi but lower expression levels in spores and at $6 \mathrm{dpi}$, suggesting their involvement in very early and late stages of plant colonization (Fig. 3B and D). Shrl and Shr7, which suppressed HR induced by $P t o(Y 207 D)$ and ATR13/RPP13, and Shr6 that suppressed HR induced by $G P A / R B P-1$, accumulated to levels roughly 1,000 fold or more in infected tissue as compared with urediniospores and germinated urediniospores (Fig. 3A, F, and G). In contrast, $S h r 3$, accumulated to more than 800 -fold $(P=0.01)$ in germinated urediniospores compared with other developmental stages of the fungus (Fig. 3C). Overall, there was no clear relationship between the developmental timing of expression and ability to suppress HR caused by specific inducers. The differences in expression patterns suggest that different effectors may be involved at different stages of fungal development within the host.

Suppression of ROS. In addition to suppressing PCD, we tested the ability of the identified effectors to suppress PTI responses.
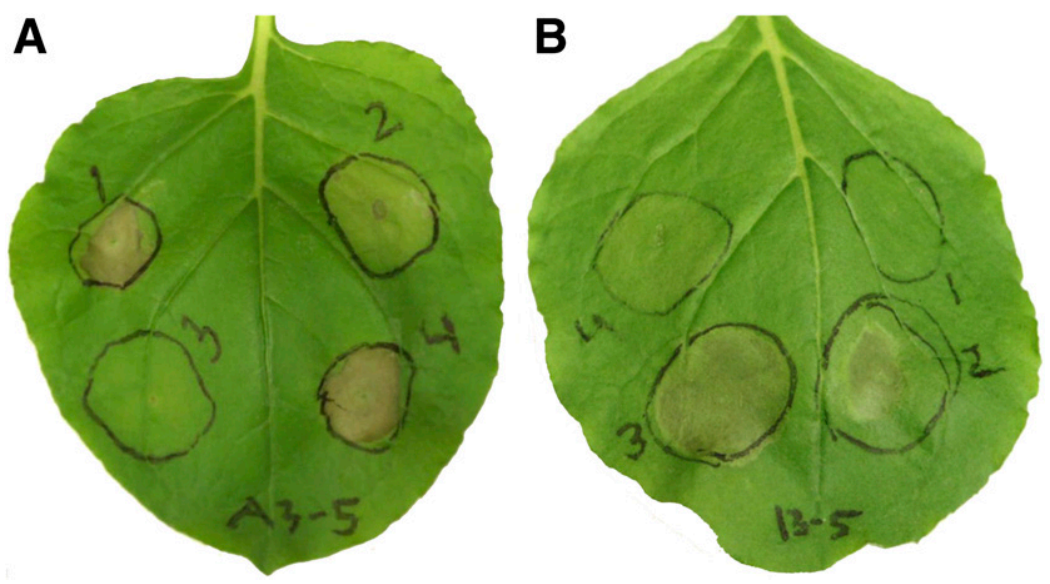

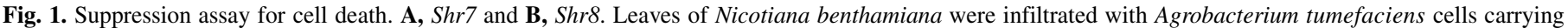

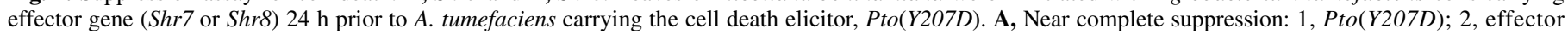

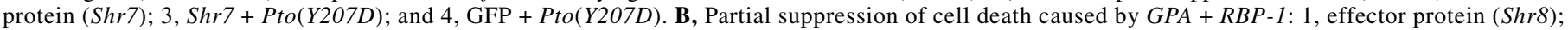
2, Shr8 + GPA+RBP-1; 3, GFP + GPA+RBP-1; and 4, AvrPtoB + GPA+RBP-1. 
Leaf punches of transiently infiltrated $N$. benthamiana plants were treated with flg22 (100 $\mathrm{nM})$ and ROS production was followed for $30 \mathrm{~min}$ immediately after elicitation. Of the nine effectors tested, consistent suppression in ROS production was observed only for $\operatorname{Shr} 7$. Significant reduction in ROS accumulation was observed in most cases when the experiment was repeated $(P<0.01)$ (Fig. 4$)$. Since it is known that accumulation of ROS accompanies PCD (Zurbriggen et al. 2010), it may be possible that $S h r 7$ interferes with PCD by down-regulating the production of ROS in the plant.

Suppression of HR in wheat. Having found a suppressive effect for Puccinia effectors in a heterologous system, we sought to translate these results in a homologous system. For this, we used an approach similar to that of Whigham et al. (2015) where a bacterial strain delivering a putative defense suppressor by the type III secretion system is infiltrated into leaves along with another strain delivering defense-eliciting effectors. For our purpose, we used Pseudomonas fluorescens EtHAn to deliver a putative suppressor and Pseudomonas syringae pv. syringae DC3000, the causative agent of bacterial speck of tomato, to deliver defense-inducing effectors. The Pseudomonas fluorescens effector to host analyzer strain (EtHAn) has been previously shown to effectively deliver Avr proteins in wheat (Upadhyaya et al. 2014). Pseudomonas syringae DC3000, on the other hand, elicits a strong HR response when syringe-infiltrated into wheat (Yin and Hulbert 2010). The HR is likely caused by multiple effectors since a DC3000 variant with several effectors deleted also elicited HR, although it was significantly weaker. Since both Pseudomonas fluorescens strain EtHAn and Pseudomonas syringae DC3000 are able to deliver effectors to wheat, their codelivery provides a suppressor assay in a homologous system.

The coding sequence of effector $S h r 7$ lacking the signal peptide was cloned into vector pEDV6 in fusion with the N-terminal signal peptide of AvrRps4 under the control of the AvrRps4 promoter. When infiltrated into wheat leaves, neither Pseudomonas fluorescens nor GFP alone cause any visible symptoms. When Pseudomonas syringae DC3000 was co-infiltrated with Pseudomonas fluorescens, a slight reduction in $\mathrm{HR}$ was observed, however this was not significantly different from the HR elicited by Pseudomonas syringae DC3000 alone (Fig. 5). On co-infiltrating Pseudomonas syringae DC3000 and Pseudomonas fluorescens EtHAn carrying Shr7, a visible suppression of HR was observed (Fig. 5).

\section{DISCUSSION}

Recent advances in bioinformatic prediction of putative effectors have provided a large repository of small secreted proteins that require functional validation. In the present study, we screened 20 effector candidates for their ability to suppress plant HR using a heterologous expression system. Our results indicate that much like many other obligate plant pathogens, Puccinia also deploys effectors to manipulate the host immune system and promote host susceptibility by suppression of defense responses. One effector, Shr7, when delivered in wheat using a Pseudomonas delivery system confirmed its ability to suppress defense responses in a homologous system.

Although a number of transient expression systems like biolistics and delivery of proteins via bacterial type III secretion system have been reported for monocots, they have not been routinely used for high-throughput screening of effector proteins (Panwar et al. 2013). Transient expression systems using biolistic or Agrobacterium transformation are inefficient in cereals and generally require analysis of individual cells. Bacterial type III secretion systems using Pseudomonas or Xanthomonas species have been used to deliver specific fungal effectors (Upadhyaya et al. 2014; Whigham et al. 2015; Yin and Hulbert 2010) but the constraints

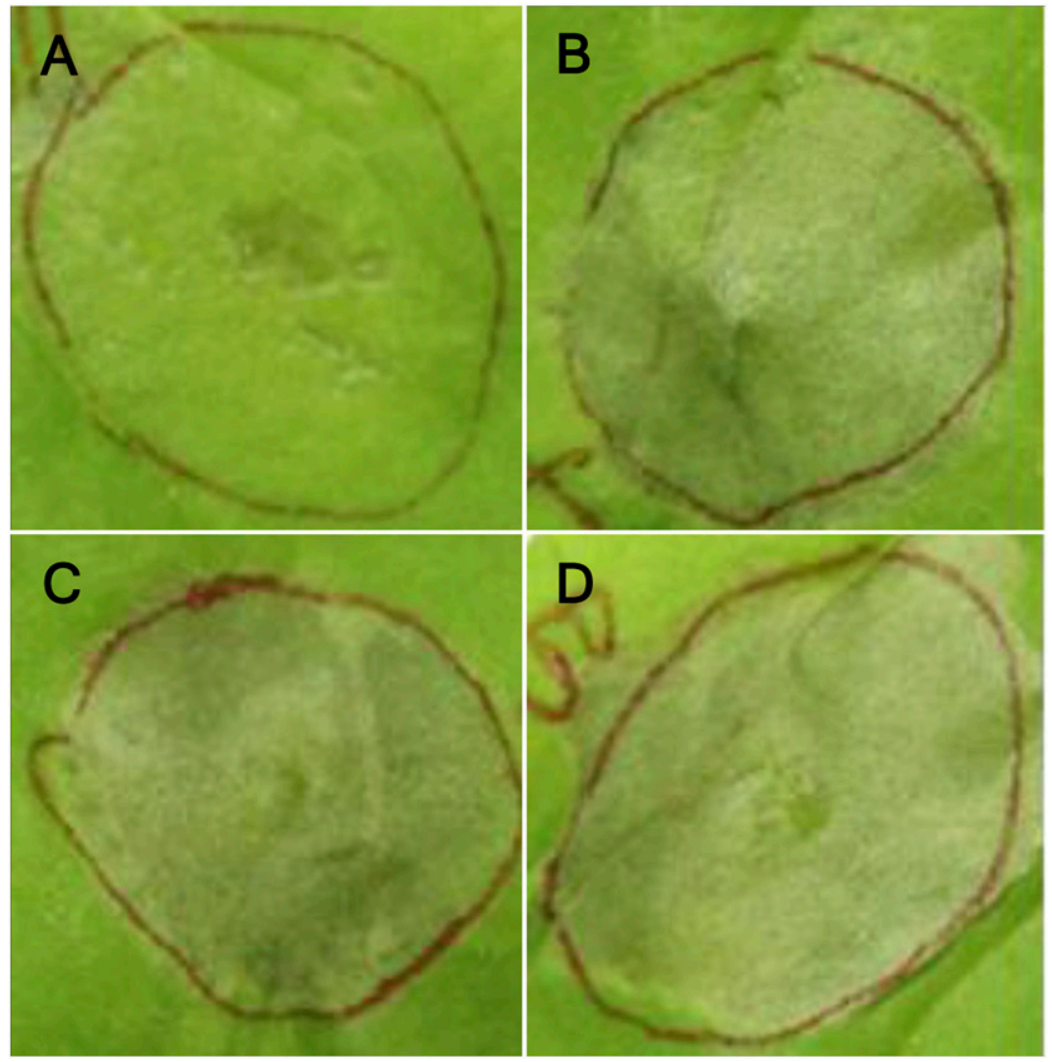

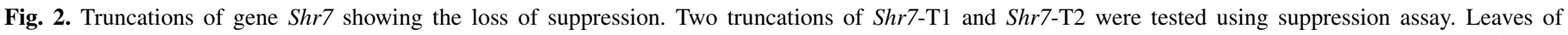

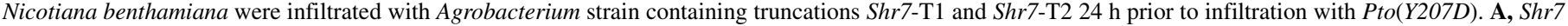
full-length protein; B, GFP- control; C, Shr7-T1; and D, Shr7-T2. 
on delivering diverse eukaryotic effector proteins are not well understood. Considering these limitations of transient gene expression systems in wheat, we used a heterologous plant species for screening effectors from Puccinia. Agrobacterium delivery into $N$. benthamiana has become a popular system for expression and co-expression of proteins, analysis of effector function (Chen et al. 2013; Song et al. 2015; Wang et al. 2011) and has been used to examine cellular localization of effectors from the rust fungus Melampsora larici-populina (Petre et al. 2015). Plant defense responses are known to be largely conserved between monocots and dicots. Recent studies show that PRRs can be transferred from taxonomically divergent plants providing durable broad-spectrum resistance to different plant species (Holton et al. 2015). In some cases, resistance genes also function after transfer from monocot species to dicots (Mendes et al. 2010). It has also been shown that pathogen effectors tend to interact with proteins that are well connected and play a central role in host cellular defense (Mukhtar et al. 2011). Given this conservation of host defense responses across plant species and the ability of Puccinia species to infect both monocots and dicots to complete their life cycle, we hypothesized that $N$. benthamiana should prove useful for screening effectors involved in defense suppression. Delivery of Shr7 in wheat using a Pseudomonas delivery system confirmed its ability to suppress defense responses in wheat. Thus, this study demonstrates the usefulness of $N$. benthamiana as an easy and effective system for phenotypic examination of effectors from rust fungi.

Nine of twenty putative effector proteins inhibited plant PCD in our transient expression assays. The nine likely represent a larger number of effectors since all but one are encoded by members of gene families with 2 to 37 predicted family members in their respective species. Effector proteins with no known function were selected since most fungal effectors characterized to date share little similarity to already known proteins (Stergiopoulos and de Wit 2009). Since the assay was performed using a nonhost plant, these effectors must supposedly target conserved components of the plant defense machinery. It is possible that some of the Puccinia effectors examined also function to suppress defense related cell death but do not function in this heterologous system. Alternatively, these other

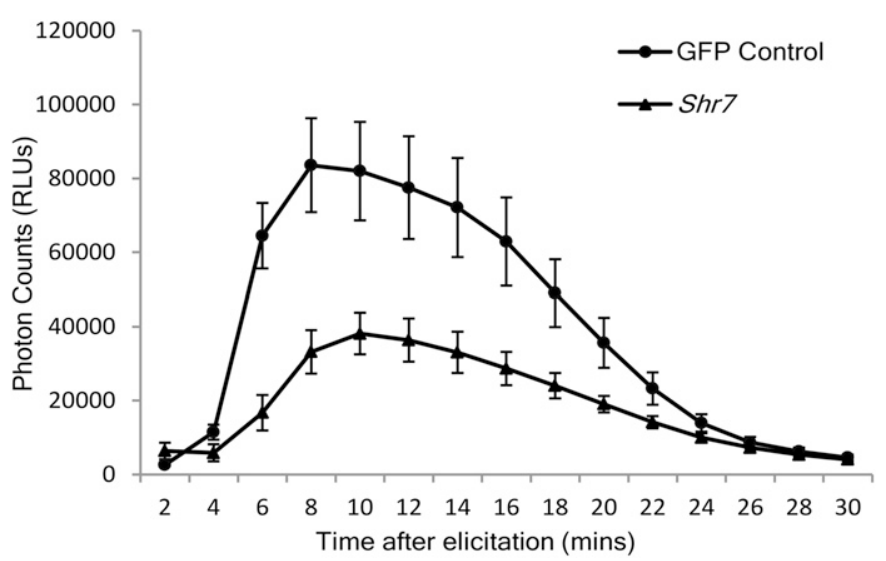

Fig. 4. Suppression of reactive oxygen species (ROS) production by Puccinia striiformis suppressor $S h r 7$. ROS response was measured over a period of 30 $\mathrm{min}$ in relative light units (RLUs) in response to $100 \mathrm{nM}$ flg22. Significance was compared with the GFP control using one-way analysis of variance followed by Tukey's honest significant difference test $(P<0.01)$. Bars represent the average of technical replicates \pm standard error $(n=12)$.
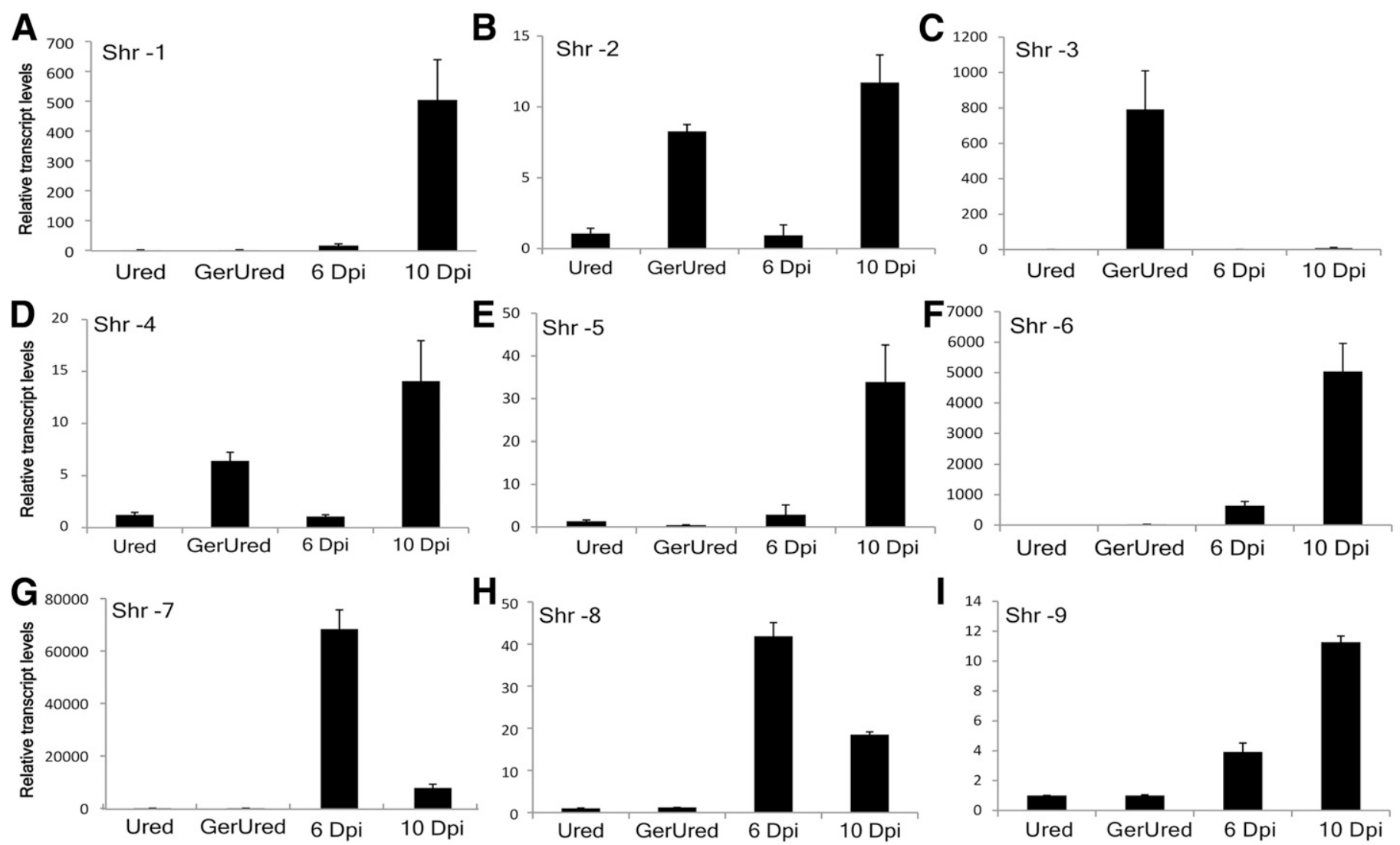

Fig. 3. Quantitative real-time PCR showing transcript level patterns for nine suppressor genes during different stages of Puccinia graminis f. sp. tritici or $P$. striiformis development and infection. A to G, Transcript levels of genes from P. striiformis. $\mathbf{H}$ and $\mathbf{I}$, Transcript levels of genes from $P$. graminis. Ured, urediniospores; GerUred, germinated urediniospores; 6 and 10 Dpi, 6 and 10 days postinoculation of wheat leaves. Standard deviation was calculated from values obtained for three biological replicates. 
protein may function to suppress defense responses that are not associated with cell death or in other processes like nutrient acquisition.

Of the nine effectors identified, $\operatorname{Shr} 3,4,5,8$, and 9 suppressed cell death induced by only one R protein, while $\operatorname{Shr} 1,2$, and 7 suppressed HR caused by two distinct $\mathrm{R}$ proteins. These results suggest that some effectors might be specific in their mode of action, while others may have multiple functions or interact with components of R-protein-mediated cell death that are common to multiple pathways. Similar effectors with broad-spectrum activities have been previously reported from Pseudomonas (Abramovitch et al. 2003). In general, most effectors suppressed either Pto $(Y 207 D)$ or RBP-1/GPA induced HR suggesting that there might be at least two different mechanisms by which these effectors operate. Previous studies aimed at understanding the mechanism of effector action have shown that most effectors work downstream of the R gene effector interaction (GimenezIbanez et al. 2009). Our results also suggest a similar mechanism of action for effectors from Puccinia, as five of the effectors tested were able to suppress $P t o(Y 207 D)$ - an auto-active mutant, capable of inducing cell death independent of effector recognition. Overall, our studies clearly demonstrate that $P$. graminis and $P$. striiformis secrete a number of effector proteins that act in different ways to suppress host immune response. Transcription profiles of the nine effectors showed differences in their expression profiles through infection and colonization. A similar pattern was observed for other putative effectors predicted from P. striiformis (Cantu et al. 2013). This variation in expression suggests that these proteins may be involved in suppression of defense responses that are activated at different time points during infection.

In addition to the HR, PAMP-triggered immunity also plays an important role during host-pathogen interactions. A hallmark of
PTI is the rapid and transient production of ROS (Torres 2010). Consequently, many plant pathogens have evolved to suppress ROS as a strategy to overcome plant innate immunity (Guo et al. 2009; Wang et al. 2011). In this study, we identified one effector, $S h r 7$, that suppressed production of ROS in addition to cell death. Previous studies with Avr3a from Phytophthora infestans, demonstrated its ability to suppress both R gene and flg22 induced ROS (ChaparroGarcia et al. 2015). It is possible that $S h r 7$, like $A v r 3 a$, acts via two different pathways. Alternatively, since ROS production is common to both ETI and PTI, it is possible $S h r 7$ interferes with in a single step leading to suppression of both PCD and flg22 induced innate immunity.

Previous studies with Pseudomonas fluorescens EtHAn have utilized the bacterium for screening Avr genes from wheat rusts (Upadhyaya et al. 2014). In this study, we adapted it for the purpose of screening for HR suppressors. Results from expression of Shr7 in wheat indicate that it can suppress nonspecific HR induced by Pseudomonas syringae DC3000. However, Shr7 only resulted in partial suppression of HR in wheat. This effect could be due to the ability of Shr7 to suppress only one or a few defense responses elicited by DC3000. Further, it remains to be tested if $S h r 7$ renders wheat susceptible to infection by Pseudomonas syringae DC3000 or interferes exclusively with pathways leading to HR. Since this effector also interferes with ROS production, we hypothesize that suppression of ROS might be central to its activity as a suppressor. In addition to validating the activity of $S h r 7$, the wheat assay results provide further evidence that Nicotiana is a good system for examining functions of effectors from rust fungi.

Understanding the functions of genes associated with fungal pathogenesis can facilitate development of rust resistant transgenic wheat. Elucidating functions of effector proteins, along with functions of their interacting partners, should help dissect the various players involved in host defense processes. Knowledge as to which

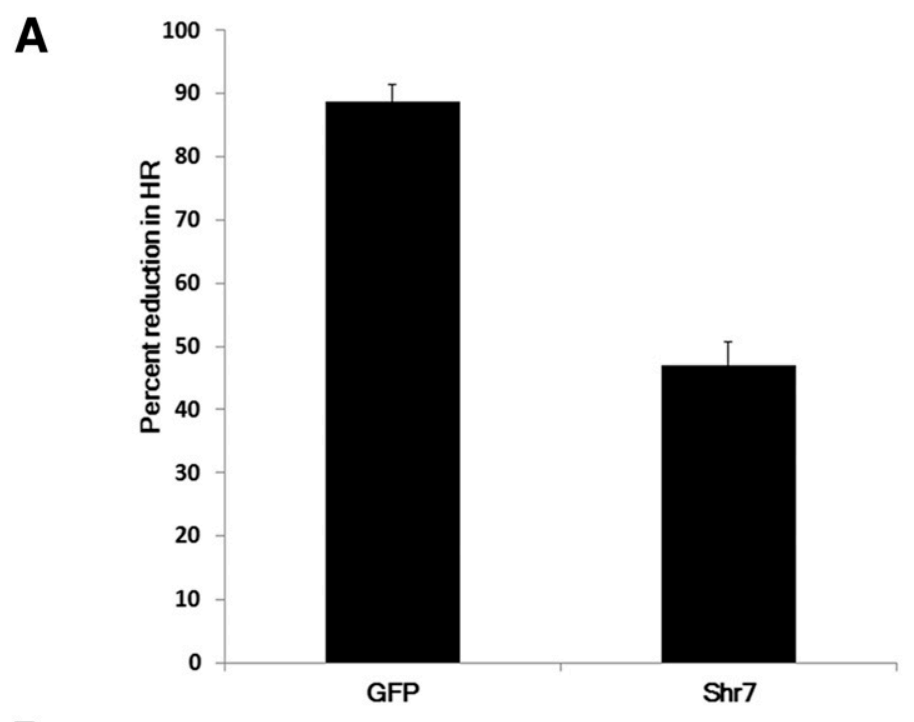

B

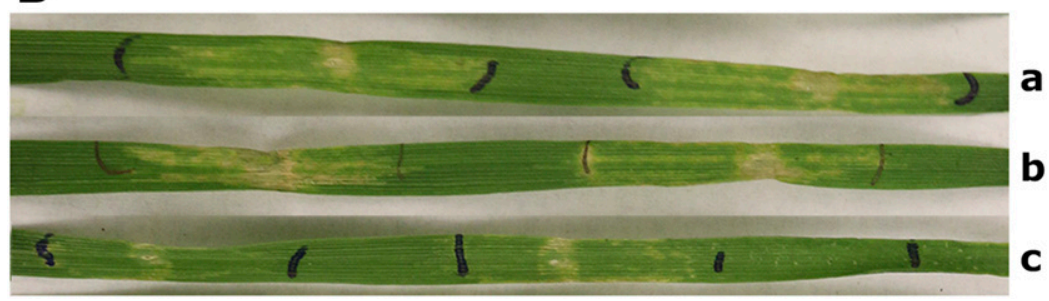

Fig. 5. Shr7 delivered via Pseudomonas fluorescens EtHAn into 10- to 14-day-old wheat leaves suppresses hypersensitive response (HR) triggered by Pseudomonas syringae pv. syringae DC3000. A, Bar graph showing percent reduction in HR caused by Shr7 ( $P$ value was $<0.001$ for both treatments). B, Syringeinfiltrated wheat leaves of cultivar Nugaines. GFP:pEDV6 served as control for co-infiltration experiments. Photographs were taken 3 days after infiltration. Experiments were repeated at least three times. a, GFP:pEDV6 + Pseudomonas syringae DC3000; b, Pseudomonas syringae DC3000; and c, Shr7:pEDV6 + Pseudomonas syringae DC3000. 
defense pathways are targeted by the fungus may help breeders select $\mathrm{R}$ genes or gene combinations that are more resistant to breakdown by the fungus. Furthermore, as some of these effectors are conserved in all three species of Puccinia that infect wheat, they may prove to be valuable candidates for engineering rust resistance.

\section{ACKNOWLEDGMENTS}

We wish to thank G. Martin for providing us the cell death constructs used in the study. This study was supported by National Institute of Food and Agriculture (Award number 2012-67013-19400). PPNS 0718, Department of Plant Pathology, College of Agriculture, Human and Natural Resource Sciences, Agricultural Research Center, Hatch Project No. WNP00663, Washington State University, Pullman, WA, 99164-6430.

\section{LITERATURE CITED}

Abramovitch, R. B., Kim, Y. J., Chen, S., Dickman, M. B., and Martin, G. B. 2003. Pseudomonas type III effector AvrPtoB induces plant disease susceptibility by inhibition of host programmed cell death. EMBO J. 22:60-69.

Ahmed, A. A., Pedersen, C., Schultz-Larsen, T., Kwaaitaal, M., Jørgensen, H. J. L., and Thordal-Christensen, H. 2015. The barley powdery mildew candidate secreted effector protein CSEP0105 inhibits the chaperone activity of a small heat shock protein. Plant Physiol. 168:321-333.

Block, A., and Alfano, J. R. 2011. Plant targets for Pseudomonas syringae type III effectors: Virulence targets or guarded decoys? Curr. Opin. Microbiol. 14:39-46.

Bos, J. I. B., Kanneganti, T. D., Young, C., Cakir, C., Huitema, E., Win, J., Armstrong, M. R., Birch, P. R. J., and Kamoun, S. 2006. The C-terminal half of Phytophthora infestans RXLR effector AVR3a is sufficient to trigger R3a-mediated hypersensitivity and suppress INF1-induced cell death in Nicotiana benthamiana. Plant J. 48:165-176.

Bruce, M., Neugebauer, K. A, Joly, D. L., Migeon, P., Cuomo, C. A, Wang, S., Akhunov, E., Bakkeren, G., Kolmer, J. A., and Fellers, J. P. 2014. Using transcription of six Puccinia triticina races to identify the effective secretome during infection of wheat. Front. Plant Sci. 4:520.

Cantu, D., Govindarajulu, M., Kozik, A., Wang, M., Chen, X., Kojima, K. K., Jurka, J., Michelmore, R. W., and Dubcovsky, J. 2011. Next generation sequencing provides rapid access to the genome of Puccinia striiformis f. sp. tritici, the causal agent of wheat stripe rust. PLoS One 6:e24230.

Cantu, D., Segovia, V., Maclean, D., Bayles, R., Chen, X., Kamoun, S., Dubcovsky, J., Saunders, D. G. O., and Uauy, C. 2013. Genome analyses of the wheat yellow (stripe) rust pathogen Puccinia striiformis f. sp. tritici reveal polymorphic and haustorial expressed secreted proteins as candidate effectors. BMC Genomics 14:270.

Catanzariti, A., Dodds, P. N., Lawrence, G. J., Ayliffe, M. A., and Ellis, J. G. 2006. Haustorially expressed secreted proteins flax rust are highly enriched avirulence elicitors. Plant Cell 18:243-256.

Catanzariti, A. M., Dodds, P. N., and Ellis, J. G. 2007. Avirulence proteins from haustoria-forming pathogens. FEMS Microbiol. Lett. 269:181-188.

Chaparro-Garcia, A., Schwizer, S., Sklenar, J., Yoshida, K., Petre, B., Bos, J. I. B., Schornack, S., Jones, A. M. E., Bozkurt, T. O., and Kamoun, S. 2015. Phytophthora infestans RXLR-WY effector AVR3a associates with dynamin-related protein 2 required for endocytosis of the plant pattern recognition receptor FLS2. PLoS One 10:e0137071.

Chen, S., Songkumarn, P., Venu, R. C., Gowda, M., Bellizzi, M., Hu, J., Liu, W., Ebbole, D., Meyers, B., Mitchell, T., and Wang, G.-L. 2013. Identification and characterization of in planta-expressed secreted effector proteins from Magnaporthe oryzae that induce cell death in rice. Mol. Plant-Microbe Interact. 26:191-202.

Dodds, P. N., Lawrence, G. J., Catanzariti, A. M., Ayliffe, M. A., and Ellis, J. G. 2004. The Melampsora lini AvrL567 avirulence genes are expressed in haustoria and their products are recognized inside plant cells. Plant Cell 16:755-768

Dou, D., Kale, S. D., Wang, X., Chen, Y., Wang, Q., Wang, X., Jiang, R. H. Y., Arredondo, F. D., Anderson, R. G., Thakur, P. B., McDowell, J. M., Wang, Y., and Tyler, B. M. 2008. Conserved C-terminal motifs required for avirulence and suppression of cell death by Phytophthora sojae effector Avr1b. Plant Cell 20:1118-1133.

Duplessis, S., Cuomo, C. A., Lin, Y.-C., Aerts, A., Tisserant, E., Veneault-Fourrey, C., Joly, D. L., Hacquard, S., Amselem, J., Canterel, B. L., Chiu, R., Coutinho, P. M., Feau, N., Field, M., Frey, P., Gelhaye, E., Goldberg, J., Grabherr, M. G., Kodira, C. D., Kohler, A., Kues, U., Lindquist, E. A., Lucas, S. M., Mago, R., Mauceli, E., Morin, E., Murat, C., Pangilinan, J. L., Park, R., Pearson, M., Quesneville, H., Rouhier, N., Sakthikumar, S., Salamov, A. A., Schmutz, J., Selles, B., Shapiro, H., Tanguay, P., Tuskan, G. A., Henrissat, B., Van de Peer, Y., Rouze, P., Ellis, J. G., Dodds, P. N.,
Schein, J. E., Zhong, S., Hamelin, R. C., Grigoriev, I. V., Szabo, L. J., and Martin, F. 2011. Obligate biotrophy features unraveled by the genomic analysis of rust fungi. Proc. Natl. Acad. Sci. USA 108:9166-9171.

Fabro, G., Steinbrenner, J., Coates, M., Ishaque, N., Baxter, L., Studholme, D. J., Körner, E., Allen, R. L., Piquerez, S. J. M., Rougon-Cardoso, A., Greenshields, D., Lei, R., Badel, J. L., Caillaud, M. C., Sohn, K. H., Van den Ackerveken, G., Parker, J. E., Beynon, J., and Jones, J. D. G. 2011. Multiple candidate effectors from the oomycete pathogen Hyaloperonospora arabidopsidis suppress host plant immunity. PLoS Pathog. 7: e1002348.

Faris, J. D., Zhang, Z., Lu, H., Lu, S., Reddy, L., Cloutier, S., Fellers, J. P., Meinhardt, S. W., Rasmussen, J. B., Xu, S. S., Oliver, R. P., Simons, K. J., and Friesen, T. L. 2010. A unique wheat disease resistance-like gene governs effector-triggered susceptibility to necrotrophic pathogens. Proc. Natl. Acad. Sci. 107:13544-13549.

Feng, F., and Zhou, J. M. 2012. Plant-bacterial pathogen interactions mediated by type III effectors. Curr. Opin. Plant Biol. 15:469-476.

Garnica, D. P., Upadhyaya, N. M., Dodds, P. N., and Rathjen, J. P. 2013. Strategies for wheat stripe rust pathogenicity identified by transcriptome sequencing. PLoS One 8:e67150.

Garnica, D. P., Nemri, A., Upadhyaya, N. M., Rathjen, J. P., and Dodds, P. N. 2014. The ins and outs of rust haustoria. PLoS Pathog. 10:e1004329.

Gimenez-Ibanez, S., Ntoukakis, V., and Rathjen, J. P. 2009. The LysM receptor kinase CERK1 mediates bacterial perception in Arabidopsis. Plant Signal. Behav. 4:539-541.

Giraldo, M. C., and Valent, B. 2013. Filamentous plant pathogen effectors in action. Nat. Rev. Microbiol. 11:800-814.

Godfrey, D., Böhlenius, H., Pedersen, C., Zhang, Z., Emmersen, J., and Thordal-Christensen, H. 2010. Powdery mildew fungal effector candidates share N-terminal Y/F/WxC-motif. BMC Genomics 11:317.

Guo, M., Tian, F., Wamboldt, Y., and Alfano, J. R. 2009. The majority of the type III effector inventory of Pseudomonas syringae pv. tomato DC3000 can suppress plant immunity. Mol. Plant-Microbe Interact. 22: 1069-1080.

Han, D. J., Key, S., Stress, C., Areas, A., Agronomy, C., and Wang, Q. L. 2015. Emerging Yr26 -virulent races of Puccinia striiformis $\mathrm{f}$. sp. tritici are threatening wheat production in the Sichuan Basin, China. Plant Dis. 99:754-760.

Holton, N., Nekrasov, V., Ronald, P. C., and Zipfel, C. 2015. The phylogeneticallyrelated pattern recognition receptors EFR and XA21 recruit similar immune signaling components in monocots and dicots. PLoS Pathog. 11: e1004602.

Hovmøller, M. S., Yahyaoui, A. H., Milus, E. A., and Justesen, A. F. 2008. Rapid global spread of two aggressive strains of a wheat rust fungus. Mol. Ecol. 17:3818-3826.

Hubbard, A., Lewis, C. M., Yoshida, K., Ramirez-Gonzalez, R. H., de Vallavieille-Pope, C., Thomas, J., Kamoun, S., Bayles, R., Uauy, C., and Saunders, D. 2015. Field pathogenomics reveals the emergence of a diverse wheat yellow rust population. Genome Biol. 16:23.

Jia, Y., McAdams, S. A., Bryan, G. T., Hershey, H. P., and Valent, B. 2000. Direct interaction of resistance gene and avirulence gene products confers rice blast resistance. EMBO J. 19:4004-4014.

Jones, J. D. G., and Dangl, J. L. 2006. The plant immune system. Nature 444: 323-329.

Kamoun, S. 2007. Groovy times: Filamentous pathogen effectors revealed. Curr. Opin. Plant Biol. 10:358-365.

Kelley, B. S., Lee, S. J., Damasceno, C. M. B., Chakravarthy, S., Kim, B. D., Martin, G. B., and Rose, J. K. C. 2010. A secreted effector protein (SNE1) from Phytophthora infestans is a broadly acting suppressor of programmed cell death. Plant J. 62:357-366.

Kolmer, J. A. 2005. Tracking wheat rust on a continental scale. Curr. Opin. Plant Biol. 8:441-449.

Lindeberg, M., Cunnac, S., and Collmer, A. 2012. Pseudomonas syringae type III effector repertoires: Last words in endless arguments. Trends Microbiol. 20:199-208

Liu, C., Pedersen, C., Schultz-Larsen, T., Aguilar, G. B., Madriz-Ordeñana, K., Hovmøller, M. S., and Thordal-Christensen, H. 2016. The stripe rust fungal effector PEC6 suppresses pattern-triggered immunity in a host speciesindependent manner and interacts with adenosine kinases. New Phytol. doi: 10.1111/nph.14034

Lorang, J. M., Sweat, T. A., and Wolpert, T. J. 2007. Plant disease susceptibility conferred by a " resistance" gene. Proc. Natl. Acad. Sci. 104:1486114866.

Mendes, B. M. J., Cardoso, S. C., Boscariol-Camargo, R. L., Cruz, R. B., Mourão Filho, F. A. A., and Bergamin Filho, A. 2010. Reduction in susceptibility to Xanthomonas axonopodis pv. citri in transgenic Citrus sinensis expressing the rice Xa21 gene. Plant Pathol. 59:68-75.

Mukhtar, M. S., Carvunis, A.-R., Dreze, M., Epple, P., Steinbrenner, J., Moore, J., and Dangl, J. L. 2011. Independently evolved virulence effectors converge onto hubs in a plant immune system network. Science 333:596-601. 
Nirmala, J., Drader, T., Lawrence, P. K., Yin, C., Hulbert, S., and Steber, C. M. 2011. Concerted action of two avirulent spore effectors activates reaction to Puccinia graminis 1 (Rpg1) -mediated cereal stem rust resistance. Proc. Natl. Acad. Sci. USA 108:14676-14681.

Oh, S. K., Young, C., Lee, M., Oliva, R., Bozkurt, T. O., Cano, L. M., Win, J., Bos, J. I. B., Liu, H. Y., van Damme, M., Morgan, W., Choi, D., Van der Vossen, E. A. G., Vleeshouwers, V. G. A. A., and Kamoun, S. 2009. In planta expression screens of Phytophthora infestans RXLR effectors reveal diverse phenotypes, including activation of the Solanum bulbocastanum disease resistance protein Rpi-blb2. Plant Cell 21:2928-2947.

Panwar, V., McCallum, B., and Bakkeren, G. 2013. Endogenous silencing of Puccinia triticina pathogenicity genes through in planta-expressed sequences leads to the suppression of rust diseases on wheat. Plant J. 73: 521-532.

Pedersen, C., Themaat, V., Ver, E., McGuffin, L., Abbott, J. C., Burgis, T. A., Barton, G., Bindschedler, L. V., Lu, X., Maekawa, T., Weßling, R., Cramer, R., Thordal-Christensen, H., Panstruga, R., and Spanu, P. D. 2012. Structure and evolution of barley powdery mildew effector candidates. BMC Genomics 13:694.

Petre, B., Saunders, D. G., Sklenar, J., Lorrain, C., Win, J., Duplessis, S., and Kamoun, S. 2015. Candidate effector proteins of the rust pathogen Melampsora larici-populina target diverse plant cell compartments. Mol. Plant-Microbe Interact. 28:689-700.

Saunders, D. G. O., Win, J., Cano, L. M., Szabo, L. J., Kamoun, S., and Raffaele, S. 2012. Using hierarchical clustering of secreted protein families to classify and rank candidate effectors of rust fungi. PLoS One 7:e29847.

Schmittgen, T. D., and Livak, K. J. 2008. Analyzing real-time PCR data by the comparative CT method. Nat. Protoc. 3:1101-1108.

Sessa, G., Ascenzo, M. D., and Martin, G. B. 2000. Thr38 and Ser198 are Pto autophosphorylation sites required for the AvrPto-Pto-mediated hypersensitive response. EMBO J.19:2257-2269.

Song, T., Ma, Z., Shen, D., Li, Q., Li, W., Su, L., Ye, T., Zhang, M., Wang, Y., and Dou, D. 2015. An oomycete CRN effector reprograms expression of plant HSP genes by targeting their promoters. PLoS Pathog. 11(12):e1005348.

Sperschneider, J., Dodds, P. N., Gardiner, D. M., Manners, J. M., Singh, K. B., and Taylor, J. M. 2015. Advances and challenges in computational prediction of effectors from plant pathogenic fungi. PLoS Pathog 11:e1004806.

Stergiopoulos, I., and de Wit, P. J. G. M. 2009. Fungal effector proteins. Annu. Rev. Phytopathol. 47:233-263.

Thomma, B. P. H. J., Nurnberger, T., and Joosten, M. H. A. J. 2011. Of PAMPs and effectors: The blurred PTI-ETI dichotomy. Plant Cell 23:4-15.

Torres, M. A. 2010. ROS in biotic interactions. Physiol. Plant. 138:414-429.

Upadhyaya, N. M., Mago, R., Staskawicz, B. J., Ayliffe, M. A., Ellis, J. G., and Dodds, P. N. 2014. A bacterial type III secretion assay for delivery of fungal effector proteins into wheat. Mol. Plant-Microbe Interact. 27:255-64.
Wang, Q., Han, C., Ferreira, A. O., Yu, X., Ye, W., Tripathy, S., Kale, S. D., Gu, B., Sheng, Y., Sui, Y., Wang, X., Zhang, Z., Cheng, B., Dong, S., Shan, W., Zheng, X., Dou, D., Tyler, B. M., and Wang, Y. 2011. Transcriptional programming and functional interactions within the Phytophthora sojae RXLR effector repertoire. Plant Cell 23:2064-2086.

Whigham, E., Qi, S., Mistry, D., Surana, P., Xu, R., Fuerst, G. S., Pliego, C., Bindschedler, L. V., Spanu, P., Dickerson, J. A., Innes, R., Nettleton, D., Bogdanove, A. J., and Wise, R. P. 2015. Broadly conserved fungal effector BEC1019 suppresses host cell death and enhances pathogen virulence in powdery mildew of barley (Hordeum vulgare L.). Mol. Plant-Microbe Interact. 28:968-983.

Whisson, S. C., Boevink, P. C., Moleleki, L., Avrova, A. O., Morales, J. G., Gilroy, E. M., Armstrong, M. R., Grouffaud, S., van West, P., Chapman, S., Hein, I., Toth, I. K., Pritchard, L., and Brich, P. R. J. 2007. A translocation signal for delivery of oomycete effector proteins into host plant cells. Nature 450:115-118

Xu, J., Linning, R., Fellers, J., Dickinson, M., Zhu, W., Antonov, I., Joly, D. L., Donaldson, M. E., Eilam, T., Anikster, Y., Banks, T., Munro, S., Mayo, M., Wynhoven, B., Ali, J., Moore, R., McCallum, B., Borodovsky, M., Saville, B., and Bakkeren, G. 2011. Gene discovery in EST sequences from the wheat leaf rust fungus Puccinia triticina sexual spores, asexual spores and haustoria, compared to other rust and corn smut fungi. BMC Genomics 12:161.

Yin, C., and Hulbert, S. 2010. Prospects for functional analysis of effectors from cereal rust fungi. Euphytica 179:57-67.

Yin, C., Jurgenson, J. E., and Hulbert, S. H. 2011. Development of a hostinduced RNAi system in the wheat stripe rust fungus Puccinia striiformis $\mathrm{f}$. sp. tritici. Mol. Plant-Microbe Interact. 24:554-561.

Yin, C., Park, J. J., Gang, D. R., and Hulbert, S. H. 2014. Characterization of a tryptophan 2-monooxygenase gene from Puccinia graminis f. sp. tritici involved in auxin biosynthesis and rust pathogenicity. Mol. Plant-Microbe Interact. 27:227-235.

Yin, C., Downey, S. I., Klages-Mundt, N. L., Ramachandran, S., Chen, X., Szabo, L. J., Pumphrey, M., and Hulbert, S. H. 2015. Identification of promising host-induced silencing targets among genes preferentially transcribed in haustoria of Puccinia. BMC Genomics 16:579.

Zheng, W., Huang, L., Huang, J., Wang, X., Chen, X., Zhao, J., Guo, J., Zhuang, H., Qiu, C., Liu, J., Liu, H., Huang, X., Pei, G., Zhan, G., Tang, C., Cheng, Y., Liu, M., Zhang, J., Zhao, Z., Zhang, S., Han, Q., Han, D., Zhang, H., Zhao, J., Gao, X., Wang, J., Ni, P., Dong, W., Yang, L., Yang, H., Xu, J. R., Zhang, G., and Kang, Z. 2013. High genome heterozygosity and endemic genetic recombination in the wheat stripe rust fungus. Nat. Commun. 4:1-10

Zurbriggen, M. D., Carrillo, N., and Hajirezaei, M.-R. 2010. ROS signaling in the hypersensitive response: When, where and what for? Plant Signal. Behav. 5:393-396. 